\title{
Selectividad del Insecticida Metamidofos en Ocho Organismos Terrestres no Destinatarios
}

\author{
J. Iannacone, ${ }^{1,2 *}$ L. Alvariño, ${ }^{2}$ Y. Murrugarra, ${ }^{2}$ A. Arrascue, M. Alayo ${ }^{2} \&$ N. Salazar ${ }^{2}$ \\ 1 Laboratorio de Invertebrados. Facultad de Ciencias Biológicas. Universidad Ricardo Palma (URP), Lima, Perú \\ ${ }^{2}$ Laboratorio de Ecofisiología Animal, Facultad de Ciencias Naturales y Matemática, \\ Universidad Nacional Federico Villarreal (UNFV), Lima, Perú
}

(Received July 27, 2006; Accepted December 13, 2007)

\begin{abstract}
RESUMEN
El organofosforado metamidofos es uno de los plaguicidas mas empleados en la agricultura peruana. El objetivo de este trabajo fue evaluar la toxicidad del metamidofos bajo dos formulaciones de diferente categoría toxicológica [Monofos ${ }^{\circledR}$, categoría Ia (extremadamente peligroso), y Tamaron $\AA$, categoría Ib (altamente peligroso)] sobre ocho organismos terrestres no destinatarios: Eisenia foetida (Savigny, 1826) (Oligochaeta: Lumbricidae), Porcellio laevis (Latreille, 1804) (Isopoda: Porcellionidae), Chrysoperla externa (Hagen, 1861) (Neuroptera: Chrysopidae), Orius insidiosus (Say, 1832) (Hemiptera: Anthocoridae), Podisus nigrispinus (Dallas, 1851) (Heteroptera: Pentatomidae), Cryptolaemus montrouzieri (Mulzant, 1853) (Coleoptera: Coccinellidae), Copidosoma koehleri (Blanchard, 1940) (Hymenoptera: Encyrtidae) y Leptomastidea abnormis (Girault, 1915) (Hymenoptera: Encyrtidae). La secuencia de mayor a menor cocientes de riesgo (CR) del metamidofos Ia fue: L. abnormis $>$ C. koehleri $>$ O. insidiosus $>$ P. laevis $>C$. externa $>C$. montrouzieri. En cambio para el metamidofos Ib fue: L. abnormis $>$ E. foetida $>$ O. insidiosus $>$ C. koehleri $>$ P. laevis $>C$. externa $>$ P. nigrispinus. Ambas formulaciones del metamidofos provocaron un efecto de mayor riesgo sobre L. abnormis. El metamidofos mostró el menor riesgo sobre $C$. externa, C. montrouzieri y P. nigrispinus a las dosis de aplicación para el control de plagas. Los CR indicaron un alto riesgo del metamidofos en el ambiente terrestre.
\end{abstract}

Palabras claves: ecotoxicología, metamidofos, plaguicida, prueba de toxicidad, riesgo ambiental.

\section{ABSTRACT}

\section{Selectivity of the insecticide metamidophos on eight not-target terrestial organisms}

The organophosphorus methamidophos is one of the most employed pesticides in Peruvian agriculture. This research aimed to evaluate the ecotoxicological effect of two formulations of methamidophos belonging to different toxicological classes [Monofos $\AA$, class Ia (extremely dangerous), and Tamaron $\AA$, class Ib (highly dangerous)] on eight non-target terrestial organisms: Eisenia foetida (Savigny, 1826) (Oligochaeta: Lumbricidae), Porcellio laevis (Latreille, 1804) (Isopoda: Porcellionidae), Chrysoperla externa (Hagen, 1861) (Neuroptera: Chrysopidae), Orius insidiosus (Say, 1832) (Hemiptera: Anthocoridae), Podisus nigrispinus (Dallas, 1851) (Heteroptera: Pentatomidae), Cryptolaemus montrouzieri (Mulzant, 1853) (Coleoptera: Coccinellidae), Copidosoma koehleri (Blanchard, 1940) (Hymenoptera: Encyrtidae) and Leptomastidea abnormis (Girault, 1915) (Hymenoptera: Encyrtidae). The sequence of higher to low risk quotients (RQ) to methamidophos Ia was: L. abnormis $>$ C. koehleri $>$ O. insidiosus $>$ P. laevis $>$ C. externa $>C$. montrouzieri. However, to methamidophos $\mathrm{Ib}$ was: L. abnormis $>$ E. foetida $>$ O. insidiosus $>$ C. koehleri $>$ P. laevis $>$ C. externa $>$ P. nigrispinus. Both formulations of methamidophos produced high risk of effect to L. abnormis and low risk to C. externa, C. montrouzieri and P. nigrispinus at doses recommended for pest control. RQ indicated that use of methamidophos is highly risky to terrestial environment.

Key words: ecotoxicology, methamidophos, pesticide, toxicity tests, environmental risk.

*Corresponding author: José Iannacone, e-mail: joseiannacone@yahoo.es 


\section{INTRODUCCIÓN}

El metamidofos es un insecticida-acaricida organofosforado de acción sistémica, de contacto y con buen poder residual. Para el hombre es altamente tóxico por vía oral, dérmica e inhalación (Hussein, 1987; Sosa-Gomez et al., 2001; Evaristo \& Baptista, 2002). Es un insecticida de amplio espectro para el control de plagas que atacan al maíz, papa, brócoli, vides, algodón, etc., siendo uno de los plaguicidas mas empleados en la agricultura peruana, bajo diferentes formulaciones (Salazar \& Araya, 2001; Iannacone et al., 2002; Prieto et al., 2002; Stoorvogel et al., 2003). Por ende, es importante determinar el nivel de riesgo ambiental del metamidofos sobre diversos componentes del ambiente terrestre usando bioensayos ecotoxicológicos (Wu et al., 2004a, b). Con este objetivo en mente fueron seleccionadas ocho especies para realizar los ensayos toxicológicos:

(1) Eisenia foetida (Savigny, 1826) (Oligochaeta: Lumbricidae) que ha sido utilizada en bioensayos ecotoxicológicos para evaluar plaguicidas (Helling et al., 2000; Vermeulen et al., 2001), debido a que son fáciles de cultivar en el laboratorio, presentan tiempos generacionales relativamente más cortos en comparación a otros oligoquetos, utilizan menores volúmenes de suelo en la cría y en el laboratorio y son ecológicamente más representativos en el ambiente terrestre (Iannacone \& Alvariño, 2004, 2005). E. foetida es un oligoqueto que ha demostrado ser adecuado para la evaluación de la toxicidad de plaguicidas empleando los criterios de la OECD (1984, 2000) y las recomendaciones de Calow (1993).

(2) Porcellio laevis (Latreille, 1804) (Isopoda: Porcellionidae), un crustáceo isópoda común en jardines y ecosistemas agrícolas en la costa central peruana. Esta especie es importante en el ambiente, pues ayuda a recircular los nutrientes y mantener los flujos de energía en el suelo, participando en los ciclos biogeoquímicos (Iannacone et al., 2001).

(3) Chrysoperla externa (Hagen, 1861) (Neuroptera: Chrysopidae), un eficiente depredador en el manejo ecológico e integrado de plagas. Sus larvas y adultos son considerados depredadores muy voraces, oófagos y larvífagos, alimentándose de amplia diversidad de presas, tales como pulgones, moscas blancas, cochinillas, huevos y larvas de lepidópteros como Spodoptera frugiperda (J.E.Smith, 1797), Spodoptera eridania (Cramer, 1782), Tuta absoluta (Meyrick, 1917), Helicoverpa zea (Boddie, 1850), Heliothis virescens (Fabricius, 1977), Cydia pomonella (Linnaeus, 1758) y Phyllocnistis citrella (Stainton, 1856), en varios cultivos (Iannacone \& Reyes, 2001; Macedo et al., 2003). C. externa tiene amplia distribución en la costa y sierra del Perú con presencia de adultos a través de todo el año, fácil crianza en cautiverio, potencial para adaptarse a varios ambientes de cultivos. Adicionalmente, existen trabajos que han evaluado su sensibilidad a varios plaguicidas (Schumuck, 1997; Iannacone \& Lamas, 2002; Carvalho et al., 2002b; Godoy et al., 2004).

(4) Orius insidiosus (Say, 1832) (Hemiptera: Anthocoridae), un depredador importante de diferentes plagas económicas en algodón, en invernadero y en plantas ornamentales. Se ha evaluado la toxicidad de varios plaguicidas sobre este chinche benéfico (Ludwig \& Oetting, 2001; Carvalho et al., 2002a; Studebaker \& Kring, 2003).

(5) Podisus nigrispinus (Dallas, 1851) (Heteroptera: Pentatomidae), un chinche que en todos sus estados de vida es depredador de larvas de lepidópteros u otras presas ocasionales. Se han evaluado algunos parámetros ecológicos como la temperatura y requerimientos nutricionales en $P$. nigrispinus (Mohaghegh et al., 1999; Oliveira et al., 2002; Vivan et al., 2002; Medeiros et al., 2003; Evangelista et al., 2004). Esta especie es muy voráz en el tercer estadío ninfal (Tillman \& Mullinix, 2004). Se ha determinado la susceptibilidad a insecticidas en formas adultas e inmaduras de $P$. nigrispinus (Zacarias et al., 1998; Evangelista et al., 2002; Torres et al., 2002, 2003; Iannacone \& Alvariño, 2005).

(6) Cryptolaemus montrouzieri (Mulzant, 1853) (Coleoptera: Coccinellidae), un depredador eficaz de varias especies de cochinillas, incluyendo entre sus presas a Planococcus citri (Risso, 1813). Las larvas y adultos son depredadores voraces, en el último estadío larval se mimetizan asumiendo un aspecto de mota blanca, lo que dificulta distinguirlas de su presa (Obrycki \& Kring, 1998; Kairo et al., 2000; Ramani et al., 2002; Serrano \& Lapointe, 2002).

(7) Leptomastidea abnormis (Girault, 1915) (Hymenoptera: Encyrtidae) es un endoparasitoide de ninfas de segundo y tercer estadio, y de hembras jóvenes de la "cochinilla de los cítricos" Planococcus citri (Risso, 1813) (Homoptera: Pseudococcidae) (Cadée \& Jacques, 1997). Esta especie de origen paleártico ha sido ampliamente criada bajo condiciones de laboratorio con fines de liberación (Tingle \& Copland, 1988; EPPO, 2002).

(8) Copidosoma koehleri (Blanchard, 1940) (Hymenoptera: Encyrtidae) es una microavispa poliembriónica parasitoide obligatoria a nivel de huevo y larva (Harvey et al., 2000; Iannacone \& Lamas, 2003). Este parasitoide actúa preferentemente sobre huevecillos del complejo de polillas de la papa como Symmetrischema plaesiosema (Turner, 1919),

T. absoluta y Phthorimaea operculella (Zeller, 1873) (Ramán et al., 1993).

Se han desarrollado diferentes protocolos de bioensayos para determinar el efecto de plaguicidas sobre la fauna benéfica (Calow, 1993; Iannacone et al., 2000; Iannacone \& Alvariño, 2005). El parámetro de toxicidad aguda más comúnmente empleado es la concentración letal media $\left(\mathrm{CL}_{50}\right)$ (en mg o mg

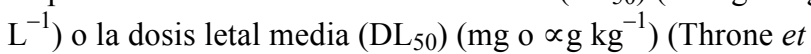
al., 1995). Los ensayos tendientes a evaluar la toxicidad crónica son también ampliamente utilizados (Calow, 1993). De esta forma, el objetivo de este trabajo fue evaluar la toxicidad aguda y crónica del metamidofos sobre estos ocho organismos terrestres no destinatarios y a partir de estos resultados evaluar el riesgo ambiental de este insecticida en el ambiente terrestre.

\section{MATERIALES Y MÉTODOS}

\section{Insecticida}

Las dos formulaciones de concentrado soluble (CS) del metamidofos $\left(\mathrm{C}_{2} \mathrm{H}_{8} \mathrm{NO}_{2} \mathrm{PS}, \mathrm{PM}=141,1\right)$ empleadas fueron 
representativas del mercado Nacional Peruano (Monofos ${ }^{\circledR}$, Categoría Ia "extremadamente peligroso" a 600 g IA L ${ }^{-1}, 104-$ 96-AG-SENASA y Tamaron®, Categoría Ib "altamente peligroso" a 600 g IA L L ${ }^{-1}$, 037-96-AG-SENASA) (Resolución Directoral 021-2003-AG-SENASA-DGSV).

El ingrediente activo (IA) metamidofos (O,S-dimetilo fosforamidotioato) presenta una toxicidad aguda oral en ratas de $\mathrm{DL}_{50}=20 \mathrm{mg} \mathrm{kg}^{-1}$ y una toxicidad aguda dérmica de $\mathrm{DL}_{50}=$ $130 \mathrm{mg} \mathrm{kg}^{-1}$. Tiene un $\log \mathrm{K}_{\mathrm{ow}}$ de $-0,66$, tiempo de vida media en el suelo es de 6 días, densidad específica de $1,34 \mathrm{~g} \mathrm{~mL}^{-1}$ a $20^{\circ} \mathrm{C}$, punto de ebullición $>150^{\circ} \mathrm{C}$, presión de vapor de $2,3 \cdot 10^{-5} \mathrm{hPa}$ a $20^{\circ} \mathrm{C}$, solubilidad en agua de $1.000 .000 \mathrm{~g} \mathrm{~L}^{-}$ 1 y en acetona de $200 \mathrm{~g} \mathrm{~L}^{-1}$ (Stoorvogel et al., 2003).

Para los ensayos la sustancia química se disolvió al 2\% en agua destilada $(\mathrm{pH}=7,2$; conductividad específica $=70$ $\propto$ mhos $\mathrm{cm}^{-1}$ ) y se aplicaron concentraciones de IA utilizando usualmente un factor de dilución de 0,5 .

\section{Diseño experimental}

Las pruebas de toxicidad aguda para $C$. externa, $O$. insidiosus, C. koehleri y L. abnormis emplearon para ambas formulaciones de metamidofos las siguientes cinco concentraciones más el control: 11,9, 23,8, 47,7, 95 y $190 \mathrm{mg}$ IA $\mathrm{L}^{-1}$, con cuatro repeticiones, en un diseño en bloque completamente aleatorio (DBCA) de 6 (concentraciones) $\cdot 4$ (especies). Para $P$. nigrispinus se emplearon cuatro concentraciones adicionales: $285,380,475$ y $570 \mathrm{mg} \mathrm{IA} \mathrm{L}^{-1}$, y para C. montrouzieri se usaron cinco concentraciones: 600, $1.200,2.400,4.800$ y $9.600 \mathrm{mg} \mathrm{IA} \mathrm{L}^{-1}$. Para $P$. laevis se usaron las siguientes dosis: $3,56,7,12,14,24,28,48$ y $56,96 \mathrm{mg} \mathrm{kg}^{-1} \mathrm{de}$ suelo. Por motivos logísticos no fue determinado el efecto toxicológico del metamidofos Ia (Monofos ${ }^{\circledR}$ ) sobre E. foetida. En cambio, para E. foetida se emplearon 6 repeticiones para los ensayos de toxicidad aguda con las siguientes dosis más el control: $3,56,7,12,14,24,28,48$ y $56,96 \mathrm{mg} \mathrm{kg}^{-1}$ de suelo. Para el bioensayo con $P$. laevis y con E. foetida, las mezclas de metamidofos con tierra y/o humus emplearon la misma calidad de tierra usada para los cultivos, previamente fue cernida con el fin de obtener una textura uniforme. C. externa y C. koehleri tuvieron también pruebas con la eclosión de los huevos y de emergencia de adultos, respectivamente, a las mismas concentraciones que las pruebas agudas.

\section{Material biológico}

Eisenia foetida: La colecta, aclimatación y cría del oligoqueto E. foetida siguió lo descrito por Iannacone \& Alvariño (2004). Las pruebas ecotoxicológicas con los oligoquetos se realizaron con cohortes de 216 especímenes de E. foetida que se obtuvieron del envase de cultivo masivo, sin considerar el grado de maduración. Se utilizadon en los ensayos lombrices de longitud total de entre 9 a $11 \mathrm{~cm}$. Los bioensayos de toxicidad se realizaron en envases cilíndricos de plástico de $12 \mathrm{~cm}$ de altura y $10 \mathrm{~cm}$ de diámetro y con un área superficial de $78,53 \mathrm{~cm}^{2}$, empleando aproximadamente $140 \mathrm{~g}$ de suelo más $70 \mathrm{~g}$ de humus de lombriz como sustrato en ensayos estáticos a $7 \mathrm{~d}$ de exposición. Las lombrices fueron colocadas bajo condiciones de oscuridad para evitar el efecto de fotólisis del producto químico. Las lombrices fueron lavadas en agua destilada y luego secadas en papel absorbente para eliminar el exceso de agua durante las lecturas. Los ensayos agudos fueron considerados válidos cuando la mortalidad no sobrepasó el $10 \%$ y un incremento de peso mayor del $20 \%$ en el grupo control (Charrois et al., 2001; Currie et al., 2005). En los ensayos agudos fueron considerados muertos los organismos que al ser pinchados con un alfiler entomológico, durante $10 \mathrm{~s}$ de observación no realizaban ningún movimiento coordinado. Para la prueba subaguda, se evaluó el efecto en el peso, luego de 7 días de exposición, el cual se determinó con una balanza semianalítica de $0,01 \mathrm{mg}$ de precisión. El peso promedio inicial de cada lombriz fue de $0,43 \pm 0,02 \mathrm{~g}$ (Iannacone \& Alvariño, 2004). Los bioensayos se realizaron bajo condiciones de temperatura de $22^{\circ} \mathrm{C} \pm 2{ }^{\circ} \mathrm{C}$ (Iannacone \& Alvariño, 2005). El fotoperiodo empleado fue de 12:12 (L:O) y la humedad relativa fluctuó entre $65 \%$ y $90 \%$.

Porcellio laevis: La colecta, aclimatación y cría de P. laevis siguió lo descrito por Iannacone et al. (2001). Para los bioensayos se seleccionaron en recipientes de plástico transparentes de 250 $\mathrm{mL}$ : (1) neonatos de segundo estadío recién eclosionados $(<12 \mathrm{~h})$ de las marsupias de las hembras oviplenas,

(2) hembras $(1,13 \pm 0,15[0,8-1,4] \mathrm{cm})$, (3) hembras con huevos $(1,11 \pm 0,17[0,8-1,5] \mathrm{cm})$ y $(5)$ machos $(1,15 \pm 0,19[0,8-1,5]$ $\mathrm{cm})$. No fue verificada diferencias en la longitud total entre hembras y machos $(\mathrm{t}=0,69 ; \mathrm{P}=0,49)$. Los experimentos se iniciaron con neonatos de segundo estadío (3 $\mathrm{mm}$ de longitud total) y de menos de 2 días de eclosionados, seleccionados al azar de los envases. Para el caso de las hembras y machos no se registró la edad de los especimenes. En cada una de las cuatro repeticiones utilizadas en estos ensayos se distribuyeron al azar 10 individuos (neonatos, hembras, hembras con huevos y machos) en envases plásticos descartables de $40 \mathrm{~mL}$ con $15 \mathrm{~g}$ de tierra, 1,5 g de humus de lombriz obtenida del Fundo Oquendo, Ventanilla, Callao, Perú ( $\left.11^{\circ} 52^{\prime} \mathrm{S}, 77^{\circ} 07^{\prime} \mathrm{W}\right)$, y 2,4 $\mathrm{mL}$ de agua destilada con las mezclas de metamidofos respectivas. Cada día se agregó $1 \mathrm{~mL}$ de agua destilada. La mortalidad se evaluó a las 3, 6, 12, 24, 48 y 72 h de exposición (Iannacone et al., 2001).

Chrysoperla externa: Las condiciones de cría para $C$. externa para la obtención de huevos y larvas siguió lo descrito por Iannacone \& Lamas (2002). Para los bioensayos, fueron empleados huevos de menos de $48 \mathrm{~h}$. Para la obtención de estados larvales, los huevos fueron incubados individualmente en pequeños viales de vidrio de $2 \mathrm{~mL}$ de capacidad. Las larvas fueron criadas también individualmente en envases de vidrio de 5,5 mL de capacidad y alimentadas ad libitum con huevos de Sitotroga cerealella (Olivier, 1819), pegados a cartulinas de 5 . $5 \mathrm{~mm}$. Las larvas fueron criadas hasta el primer estadio de desarrollo y se emplearon cohortes de especímenes entre 24 a 48 h. Se escogió este estadío debido a que enbioensayos ecotoxicológicos previos se observó que era el estado más vulnerable (Iannacone \& Lamas, 2002). 
Ecotoxicidad por inmersión - Se realizaron las aplicaciones tópicas en huevos de C. externa por inmersión durante $5 \mathrm{~s}$, en las diluciones seleccionadas de metamidofos y en agua destilada (grupo control). Después de la inmersión, los huevos fueron colocados en papel Tissue ${ }^{\circledR}$ por 10 min para absorber lo restante de las soluciones acuosas y permitir el secado ambiental. Se trataron 40 huevos por cada concentración (10 especímenes por repetición). Los huevos fueron individualizados en viales de vidrio de $5 \mathrm{~mL}$ de capacidad con tapas de algodón. Después de las aplicaciones tópicas, los viales se mantuvieron en oscuridad bajo condiciones de cría, realizándose las lecturas hasta la eclosión de los huevos ( 120 h).

Ecotoxicidad por contacto-residual - Estos ensayos se llevaron a cabo para las larvas de primer estadio, no alimentadas previamente. El metamidofos disueltos en agua destilada se aplicó en viales de vidrio $(25 \propto \mathrm{L}$ por cada vial de $5 \mathrm{~mL}$ de capacidad). En cada vial de vidrio se esparció homogéneamente en sus paredes y base, con la ayuda de un hisopo de base de madera, los $\propto \mathrm{L}$ determinados de la sustancia química colocada en su interior y posteriormente se permitió el secado de los viales a temperatura ambiente durante $2 \mathrm{~h}$ o alternativamente a una temperatura de $35^{\circ} \mathrm{C}$ en una estufa durante $1 \mathrm{~h}$ con sus respectivos tapones de algodón. Posteriormente, en el interior de cada uno de los viales ya secos, se depositó una larva de primer estadío. Se consideró un total de 5 larvas por repetición. Los viales se mantuvieron en condiciones de cría y oscuridad y se observó la mortalidad acumulada a $48 \mathrm{~h}$ de exposición.

Podisus nigrispinus: Los huevos (de menos de $48 \mathrm{~h}$ de edad) se obtuvieron de cultivos estandarizados del PNCBSENASA, a partir de los cuales se realizaron las crianzas masivas en condiciones de laboratorio, con el fin de obtener ninfas de I estadío para los bioensayos de susceptibilidad. Las ninfas de primer estadío recién emergidas $(<24 \mathrm{~h})$, se aclimataron masivamente en el laboratorio en envases cuadrangulares de plástico de $12 \mathrm{~cm} \cdot 30 \mathrm{~cm} \cdot 20 \mathrm{~cm}$. Estas ninfas se alimentaron con larvas de $S$. eridania, obtenidos del PNCB-SENASA. La crianza parcial se llevó a cabo bajo condiciones no controladas de temperatura y humedad relativa. Sin embargo la temperatura fluctuó entre 18 y $22^{\circ} \mathrm{C}$ (media $=$ $20^{\circ} \mathrm{C}$ ) y la humedad relativa entre $65 \%$ y $90 \%$. La crianza se realizó bajo un fotoperiodo 12:12 (L:O). Para los bioensayos, fueron empleadas ninfas I $<$ de $48 \mathrm{~h}$. El indicador de la prueba fue la mortalidad. Se trataron 20 ninfas por cada concentración (5 especímenes por repetición). Después de las aplicaciones, los envases se mantuvieron cerrados en oscuridad bajo condiciones de cría, realizándose las lecturas a 1, 3, 6, 12, 24 y 48 h de exposición.

Ecotoxicidad por inmersión - Se realizaron las aplicaciones en ninfas de $P$. nigrispinus por inmersión durante $5 \mathrm{~s}$ en placas de petri, en las diluciones de la sustancia y en agua destilada. Después de la inmersión, las ninfas fueron colocadas en papel Tissue ${ }^{\circledR}$ por 10 min para absorber lo restante de las soluciones acuosas y permitir el secado ambiental.

Ecotoxicidad por contacto - El metamidofos disuelto en agua destilada se aplicó en viales de vidrio $(25 \propto \mathrm{L}$ por cada vial de $3 \mathrm{~mL}$ ). En cada vial de vidrio se esparció homogéneamente en sus paredes y base, con la ayuda de un hisopo de base de madera, los $\mathrm{mL}$ determinados de la sustancia química colocada en su interior y posteriormente se permitió el secado de los viales a temperatura ambiente durante $2 \mathrm{~h}$ con sus respectivos tapones de algodón.

Cryptolaemus montrouzieri: Las pupas $(<$ de $72 \mathrm{~h}$ de edad) se obtuvieron de cultivos estandarizados del PNCBSENASA, a partir de los cuales se realizaron las crianzas masivas en condiciones de laboratorio, con el fin de obtener adultos para los bioensayos de susceptibilidad. Los adultos recién emergidos $(<24 \mathrm{~h})$, se aclimataron masivamente en el laboratorio en envases circulares de plástico de $10 \mathrm{~cm}$ de diámetro. La crianza parcial se llevó a cabo bajo condiciones no controladas de temperatura y humedad relativa. Sin embargo la temperatura fluctuó entre 20 y $24^{\circ} \mathrm{C}\left(\right.$ media $\left.=22^{\circ} \mathrm{C}\right)$ y la humedad relativa entre $65 \%$ y $90 \%$. La crianza se realizó bajo un fotoperiodo 12:12 (L:O). Para los bioensayos, fueron empleados adultos < de $96 \mathrm{~h}$. Los envases de plástico de $5 \mathrm{~cm}$ de alto $\cdot 4,5 \mathrm{~cm}$ de diámetro fueron cubiertos con una gasa, a los que se les agregó $50 \mathrm{~mL}$ de cada una de las concentraciones acuosas con la ayuda de una pipeta automática con puntas descartables y luego con un hisopo se esparcieron homogéneamente sobre la superficie interna del vial de vidrio. El indicador para la prueba fue la mortalidad. Se trataron 20 adultos por cada concentración (5 especímenes por repetición).

Evaluación de la mortalidad de $P$. laevis, $C$. externa, $P$. nigrispinus y $\boldsymbol{C}$. montrouzieri: Se consideraron muertos los individuos que no realizaron ningún movimiento coordinado en el envase durante $15 \mathrm{~s}$ de observación al microscopio estereoscopio a $10 \cdot$ de aumento, con la ayuda de un alfiler entomológico. Las pruebas de sensibilidad se realizaron bajo condiciones de oscuridad, para evitar el efecto de fotólisis.

Orius insidiosus, Copidosoma koehleri y Leptomastidea abnormis: El chinche pirata $O$. insidiosus, y las microavispas $C$. koehleri y L. abnormis fueron obtenidos de colonias mantenidas por el PNCB-SENASA. O. insidiosus fue criada en el laboratorio en esquejes de camote con huevos de $S$. cerealella. C. koehleri fue criada en el laboratorio sobre huevos y larvas de $P$. operculella bajo condiciones de temperatura $24 \pm 2{ }^{\circ} \mathrm{C}$ y $12 \mathrm{~h}$ de fotoperíodo. En adición, $L$. abnormis fue criada en el laboratorio sobre de ninfas de segundo y tercer estadio, y hembras de $P$. citri. Los ensayos de contacto residual se llevaron a cabo para los adultos de $O$. insidiosus, C. koehleri y L. abnormis. Los viales de $2,5 \mathrm{~mL}$ fueron cubiertos con una torunda de algodón, a los que se les agregó 12,5 $\mathrm{mL}$ a los viales de cada una de las concentraciones acuosas con la ayuda de una pipeta automática con puntas descartables y luego con un hisopo se esparcieron homogéneamente sobre la superficie interna del vial de vidrio. Posteriormente se permitió el secado de los viales a temperatura ambiente durante $2 \mathrm{~h}$ o alternativamente a una temperatura de $35^{\circ} \mathrm{C}$ en una estufa durante $1 \mathrm{~h}$ con sus respectivos tapones o torundas de algodón. Los experimentos se realizaron con cohortes de adultos $<$ de $48 \mathrm{~h}$ de emergidos, no alimentados antes del bioensayo. Se empleó individuos 
machos y hembras al azar, tomados de los frascos de emergencia de adultos de $O$. insidiosus, C. koehleri y L. abnormis. Para cada una de las pruebas se utilizó 120 individuos, los cuales se consideraron muertos cuando no se posaron sobre el vial de vidrio y se encontraban con las patas dirigidas hacia arriba, durante $10 \mathrm{~s}$ de observación al microscopio estereoscopio. El tratamiento control consistió en agua destilada. Se utilizó cuatro repeticiones (1 vial $=1$ repetición) por tratamiento. Cada bioensayo se realizó por duplicado. Se condujeron ensayos de toxicidad aguda estáticos de residuos en oscuridad. Los viales se mantuvieron en condiciones de cría y oscuridad y se observó la mortalidad acumulada a diferentes h de exposición, para $O$. insidiosus hasta $12 \mathrm{~h}$, para $C$. koehleri hasta $48 \mathrm{~h}$ y para L. abnormis hasta $12 \mathrm{~h}$. Las lecturas se continuaron siempre y cuando la mortalidad en el control no fuera mayor al 20\%. En adición, se efectuaron las aplicaciones tópicas por inmersión durante $5 \mathrm{~s}$ en placas petri usando larvas momificadas de $P$. operculella parasitadas por C. koehleri. Después de la inmersión, las larvas momificadas fueron colocadas en papel Tissue ${ }^{\circledR}$ por 10 min para absorber lo restante de las soluciones acuosas, permitiendo el secado ambiental por $1 \mathrm{~h}$. Se trataron 20 larvas momificadas por cada formulación de metamidofos evaluado. Las larvas momificadas se colocaron en viales de $12 \mathrm{~mL}$. Después de las aplicaciones tópicas, los viales se mantuvieron cubiertos en oscuridad bajo condiciones de cría, realizándose las lecturas hasta la eclosión sobre el $85 \%$ en el agua destilada de los adultos de C. koehleri de las larvas momificadas de P. operculella. El porcentaje de emergencia de C. koehleri se calculó contando el número de microavispas emergidas de una larva momificada de $P$. operculella, dividiéndolo entre el número total de cámaras parasitadas por larva (además se contó el número de adultos formados no emergidos y el número de formas inmaduras de C. koehleri).

\section{Tratamiento de datos}

En todos los casos, la eficacia de los tratamientos y las repeticiones se evaluaron a través de un análisis de varianza (ANDEVA) de dos vías con prueba complementaria de Tukey. Los datos fueron previamente normalizados (transformación de los datos a raíz cuadrada del arcoseno). Las $\mathrm{C}(\mathrm{D}) \mathrm{L}(\mathrm{E}) \mathrm{S}_{50}$ se calcularon usando el programa computarizado Probit versión 1,5. El modelo de regresión fue verificado usando el estadístico Chi-cuadrado. Se empleó el paquete estadístico SPSS, versión 13 para Windows XP para el cálculo de los estadísticos descriptivos e inferenciales a un nivel de significancia de 0,05.

\section{Evaluación del Riesgo Ambiental (ERA)}

Se empleó está técnica para determinar la naturaleza y magnitud de riesgo de metamidofos en ambas categorías toxicológicas (Ia y Ib), usando los escenarios más críticos y de peor exposición en el ambiente terrestre. Se siguió el protocolo propuesto por Gonzalez-Valero et al. (2000) y Iannacone \& Alvariño (2005). Se usó un nivel crítico de 0,5 para los ensayos de toxicidad aguda y de 1 para la toxicidad sub-aguda.

\section{RESULTADOS}

Se determinó el efecto toxicológico agudo $\left(\mathrm{DL}_{50}\right)$ del metamidofos Ib sobre E. foetida a $144 \mathrm{~h}$ de exposición (Tabla 1). No se obtuvo el efecto toxicológico del metamidofos Ia. Se observó en el metamidofos Ib un incremento en el porcentaje de mortalidad de E. foetida de 50,2\% entre las dosis de 3,56 a $56,96 \mathrm{mg} \mathrm{IA} \mathrm{kg}^{-1}$ de suelo y un efecto subagudo en el peso de E. foetida y todas las dosis evaluadas (Tabla 1). En adición, en todos los casos se encontraron diferencias significativas entre los pesos iniciales y finales de E. foetida para las cinco dosis del metamidofos $\mathrm{Ib}(\mathrm{t}=8,08-274 ; \mathrm{P}=0,000)$. A $3,56 \mathrm{mg}$ IA $\mathrm{kg}^{-1}$ de suelo, se encontró un menor porcentaje de mortalidad y un mayor peso final en $E$. foetida que a $28,48 \mathrm{mg} \mathrm{IA} \mathrm{kg}^{-1}$.

Se encontró un aumento de la mortalidad de hembras con huevos y sin huevos de P. laevis con las dosis crecientes del metamidofos Ia en el suelo a 24 y 48 h de exposición (Figura 1a y b). No se encontró ningún efecto del metamidofos Ia en el porcentaje de mortalidad de $P$. laevis entre las $3 \mathrm{~h} \mathrm{y} 12 \mathrm{~h}$ de exposición, por lo que en la gráfica solo se presentan los efectos de toxicidad a $12 \mathrm{~h}, 24 \mathrm{~h} \mathrm{y} 48 \mathrm{~h}$ (Figuras 1a y b). No se observaron diferencias numéricas notorias entre los valores de $\mathrm{DL}_{50}$ (mg IA kg ${ }^{-1}$ de suelo) a $48 \mathrm{~h}$ de exposición entre hembras sin huevos $(28,8)$ y hembras con huevos $(22,8)$ de $P$. laevis $(\mathrm{t}=$ $1,89 ; \mathrm{P}=0,11)$. Para el caso del metamidofos $\mathrm{Ib}$, se vio un incremento de la mortalidad de neonatos, machos y hembras de $P$. laevis con las dosis crecientes del metamidofos $\mathrm{Ib}$ en el suelo, mayormente a 12, 24, 48 y 72 h de exposición (Figuras $1 \mathrm{c}, 1 \mathrm{~d}$ y 1e). No se encontró ningún efecto del metamidofos $\mathrm{Ib}$ en el porcentaje de mortalidad de neonatos a las $3 \mathrm{~h}$, machos a las $3 \mathrm{~h}$ y $6 \mathrm{~h}$, y hembras a las $3 \mathrm{~h}$ y $6 \mathrm{~h}$ de exposición de $P$. laevis (Figuras 1c, 1d y 1e).

Se observaron diferencias significativas entre los valores de $\mathrm{DL}_{50}$ (mg IA kg${ }^{-1}$ de suelo) a $48 \mathrm{~h}$ de exposición entre neonatos $(20,3)$, a $48 \mathrm{~h}$ de exposición para machos $(13,4)$ y hembras $(16,4)$ de $P$. laevis. Las hembras de P. laevis fueron $75 \%$ más sensibles al metamidofos Ib que al Ia.

A las $48 \mathrm{~h}$ de exposición por contacto, las larvas de primer estadio de C. externa fueron $136 \%$ más sensibles al metamidofos Ib que al Ia, en términos de la $\mathrm{CL}_{50}$ (Tabla 1). En contraste el porcentaje de no eclosión de huevos de $C$. externa fue $139 \%$ más sensible al metamidofos Ia que al $\mathrm{Ib}$ en relación a su $\mathrm{CE}_{50}$ (Tabla 1 ).

No se observó efecto de contacto y de inmersión del metamidofos $\mathrm{Ib}$ sobre las ninfas $\mathrm{I}$ de $P$. nigrispinus a ninguna de las 9 concentraciones empleadas $(11,9$ a $570 \mathrm{mg}$ IA $\mathrm{L}^{-1}$ ), entre $1 \mathrm{~h} \mathrm{y} 48 \mathrm{~h}$ de exposición. En el caso de los adultos de $C$. montrouzieri se encontró que el metamidofos Ia produjo a $1 \mathrm{~h}$ de exposición un $80 \%$ de mortalidad a 600 $\mathrm{mg} \mathrm{L}^{-1}$, registrándose una mortalidad de $100 \%$ en el resto de las concentraciones. A $4 \mathrm{~h}$ de exposición, todas las concentraciones produjeron $100 \%$ de mortalidad.

Al evaluar el efecto de contacto del metamidofos Ia sobre los adultos de O. insidiosus se vio que entre $1-2 \mathrm{~h}$ a $12 \mathrm{~h}$ de exposición, la $\mathrm{CL}_{50}$ varió entre 19,3 y $144 \mathrm{mg} \mathrm{IA} \mathrm{L}^{-1}$ (Tabla 
2). Para el caso del metamidofos Ib, se observó que entre 1$2 \mathrm{~h}$ a $12 \mathrm{~h}$ de exposición, la $\mathrm{CL}_{50}$ varió entre 10,3 y $281 \mathrm{mg}$ IA L $^{-1}$ para los adultos de $O$. insidiosus (Tabla 2 ). A $12 \mathrm{~h}$ de exposición los adultos de $O$. insidiosus fueron $87,4 \%$ más sensibles al meta-midofos Ib que al Ia.

En el caso de los adultos del microhimenoptero C. koehleri, el metamidofos Ia se vio que entre 1-2 h a 48 h de exposición, la $\mathrm{CL}_{50}$ varió entre 12,1 y $>190 \mathrm{mg} \mathrm{IA} \mathrm{L}^{-1}$ (Tabla 3). Para el caso del metamidofos Ib, se observó que entre 1-2 h a $48 \mathrm{~h}$ de exposición, la $\mathrm{CL}_{50}$ varió entre $11,1 \mathrm{y}>190 \mathrm{mg} \mathrm{IA} \mathrm{L}^{-1}$ para los adultos de C. koehleri (Tabla 3). A $48 \mathrm{~h}$ de exposición los adultos de $C$. koehleri tuvieron similar sensibilidad al metamidofos Ia y Ib (Tabla 3). Los porcentajes de emergencia de los adultos de C. koehleri, mostraron para la concentración de $190 \mathrm{mg} \mathrm{IA} \mathrm{L}^{-1}$, efecto solo en el metamidofos Ia (Tabla 3).

Para los adultos del microhimenoptero L. abnormis, en el metamidofos Ia se vio que entre $1-2 \mathrm{~h}$ a $12 \mathrm{~h}$ de exposición, la $\mathrm{CL}_{50}$ varió entre 2,6 y $15 \mathrm{mg} \mathrm{IA} \mathrm{L}^{-1}$ (Tabla 4). Para el caso del metamidofos Ib, se observó que entre $1-2 \mathrm{~h}$ a $12 \mathrm{~h}$ de exposición, la $\mathrm{CL}_{50}$ varió entre 6,7 y $167 \mathrm{mg} \mathrm{IA} \mathrm{L}^{-1}$ para los adultos de L. abnormis (Tabla 4). A $12 \mathrm{~h}$ de exposición los adultos de L. abnormis fueron $157 \%$ más sensibles al metamidofos Ia que al Ib.

Así, la secuencia relativa de mayor a menor cocientes de riesgo (CR) del metamidofos Ia fue: L. abnormis $>$ C. koehleri $>O$. insidiosus $>$ P. laevis $>C$. externa $>C$. montrouzieri. En cambio para el metamidofos Ib fue: L. abnormis $>$ E. foetida $>$ O. insidiosus $>$ C. koehleri $>$ P. laevis $>$ C. externa $>P$. nigrispinus.

Esta comparación relativa es procedente desde una perspectiva ecotoxicológica, ya que considera los escenarios propios de exposición de cada especie. Sin embargo, las vias de exposición para cada especie son diferentes y, consecuentemente, los procesos bioquímicos asociados también deben diferir.

La ERA del metamidofos categoría Ia y Ib, mostró en general para las ocho especies en el ambiente terrestre un alto riesgo para todas las especies, pues los cocientes de riesgo (CR) fluctuaron entre 3 y 807 para el metamidofos categoría Ia y entre 3,7 y 313 para la categoría Ib (Tabla 5). Ambas formulaciones del metamidofos provocaron un efecto de riesgo sobre $L$. abnormis.

A excepción de la microavispa L. abnormis la formulación Ia y $\mathrm{Ib}$ del metamidofos provocaron un efecto de riesgo sobre los organismos del suelo. El metamidofos mostró el menor riesgos sobre C. externa, C. montrouzieri y $P$. nigrispinus a las dosis de aplicación para el control de plagas.

\section{DISCUSIÓN}

El uso potencial de organismos biológicos como bioindicadores en ensayos de ecotoxicidad está ampliamente documentado (Rombke et al., 2006). Su principal utilidad de emplearlos en ecotoxicología es la de mostrar los efectos del tóxico a nivel individual, y así inferir los efectos a nivel poblacional (Iannacone \& Alvariño, 2005). El empleo de ocho especies para evaluar los efectos colaterales del metamidofos nos muestra que se puede obtener información útil. La combinación de las ocho especies fue seleccionada para incluir diferentes grupos tróficos: dos desintegradores, tres depredadores y tres parasitoides; así como diferentes estados de desarrollo: huevos, larvas y adultos. Iannacone \& Alvariño (2005) evaluaron la toxicidad del insecticida cartap empleando ocho organismos animales no destinatarios de diferentes grupos tróficos y estados de desarrollo, encontrando un alto efecto de este insecticida sobre los parasitoides.

Ambas formulaciones del metamidofos (Ia y Ib) no provocaron los mismos resultados y secuencia en términos de mortalidad en los ocho organismos evaluados (Armenta et al., 2003). Así, la secuencia de mayor a menor cocientes de riesgo (CR) del metamidofos Ia fue: L. abnormis $>C$. koehleri $>O$. insidiosus $>$ P. laevis $>$ C. externa $>C$. montrouzieri. En cambio para el metamidofos Ib fue: L. abnormis $>$ E. foetida $>$ O. insidiosus $>C$. koehleri $>P$. laevis $>C$. externa $>P$. nigrispinus. La ventaja del empleo de los CR para comparar en forma relativa las diferentes especies empleadas es que no son dependientes de valores de $\mathrm{CL}_{50}$ en $\mathrm{mg} \mathrm{IA} \mathrm{L}^{-1}$ o de $\mathrm{DL}_{50}$ en mg IA kg ${ }^{-1}$ de suelo, las cuales no son comparables entre sí. Los tiempos de exposición variaron entre 4 h y 144 $\mathrm{h}$ en dependencia con las diferentes especies empleadas en los bioensayos, lo cual podría dificultar la comparación en forma relativa de los $\mathrm{CR}$.

Aunque se esperaba que en todos los casos la formulación de metamidofos Ia presentara los mayores efectos toxicológicos en los bioensayos realizados en comparación con la $\mathrm{Ib}$, se encontraron resultados que variaban según la especie analizada, estas diferencias encontradas pueden ser atribuidas a que la composición de los inertes es diferente en ambas formulaciones, pudiendo el "inerte" contribuir a la toxicidad del producto formulado (Iannacone \& Gutierrez, 1999).

El metamidofos en sus dos formulaciones de categorías Ia y Ib, no mostraron los mismos efectos toxicológicos agudos en todas las especies de invertebrados analizados. En contraste, se ha visto que el metamidofos produjo poco efecto tóxico en otras especies de enemigos naturales como la microavispas parasitoides Cotesia plutellae (Kurdjumov, 1912) (Hymenoptera: Braconidae) y en Diaeretiella rapae (M'Intosh, 1855) (Hymenoptera: Aphidiidae), atribuyéndolese a la degradación oxidativa y a la reacciones hidrolíticas, en el proceso de detoxificación del metamidofos (Wu et al., 2004a, b). En adición, Petcharat (1998) encontró un menor efecto del metamidofos sobre la avispa parasitoide Diachasmimorpha longicaudata (Ashmead, 1905) en comparación con otros tres insecticidas como malation, metil paration y carbaril. Sin embargo, Figuls et al. (2006) encontraron en hojas de tomate que el metamidofos es considerado persistente al encontrarse toxicidad aguda residual a los 30 días después de la aplicación en los chinches depredadores Dicyphus tamaninii (Wagner, 1951) y Macrolophus caliginosus (Wagner, 1951) (Hemiptera: Miridae). Se ha observado que el metamidofos es altamente tóxico para la abeja Apis mellifera Linnaeus, $1758\left(\mathrm{DL}_{50}=1,37\right.$ $\propto \mathrm{g} \mathrm{abeja}^{-1}$ ) (Fiedler, 1987; USEPA, 1998). 
Tabla 1 - Efecto del metamidofos en la mortalidad y en el peso final de Eisenia foetida (Lumbricidae) a 144 h de exposición y en el porcentaje de no eclosión de huevos y de mortalidad larvaria de Chrysoperla externa (Chrysopidae) a $48 \mathrm{~h}$ de exposición. Letras minúsculas iguales en una misma columna indican que los porcentajes de mortalidad son estadísticamente iguales $(\mathrm{p} \geq 0,05) . \mathrm{a}=\mathrm{mg} \mathrm{kg}^{-1}$ de suelo. ND $=$ no determinado.

\begin{tabular}{|c|c|c|c|c|c|c|c|}
\hline \multirow{2}{*}{\multicolumn{3}{|c|}{ Eisenia foetida }} & \multicolumn{5}{|c|}{ Chrysoperla externa } \\
\hline & & Peso final (g) & & \multicolumn{2}{|c|}{ \% no eclosión } & \multicolumn{2}{|c|}{$\%$ mortalidad } \\
\hline $\begin{array}{c}\text { Dosis } \\
\left(\mathrm{mg} \mathrm{kg}^{-1} \text { de }\right. \\
\text { suelo) }\end{array}$ & $\begin{array}{c}\text { metamidofos } \\
\left(\text { Tamaron }{ }^{\circledR},\right. \\
\text { Clase Ib) }\end{array}$ & $\begin{array}{c}\text { metamidofos } \\
\text { (Tamaron }{ }^{\circledR} \text {, } \\
\text { Clase Ib) }\end{array}$ & $\underset{\left(m g L^{-1}\right)}{\text { Concentrán }}$ & $\begin{array}{c}\text { metamidofos } \\
\text { (Monofos } ₫ \text {, } \\
\text { Clase Ia) }\end{array}$ & $\begin{array}{c}\text { metamidofos } \\
\text { (Tamaron }{ }^{\circledR}, \\
\text { Clase Ib) }\end{array}$ & $\begin{array}{c}\text { metamidofos } \\
\text { (Monofos } ₫ \text {, } \\
\text { Clase Ia) }\end{array}$ & $\begin{array}{c}\text { metamidofos } \\
\text { (Tamaron }{ }^{\circledR}, \\
\text { Clase Ib) }\end{array}$ \\
\hline Control & $0 \mathrm{a}$ & $0,46 a$ & Control & $0 \mathrm{a}$ & $0 \mathrm{a}$ & $0 \mathrm{a}$ & $0 \mathrm{a}$ \\
\hline 3,56 & $66,66 \mathrm{~b}$ & $0,22 b$ & 11,9 & $11,3 \mathrm{ab}$ & $10,4 \mathrm{ab}$ & $5,5 \mathrm{a}$ & $17,5 b c$ \\
\hline 7,12 & $75 b$ & $0,19 b c$ & 23,8 & $22,4 \mathrm{~b}$ & $13,6 a b$ & $18,6 \mathrm{~b}$ & $30 \mathrm{~cd}$ \\
\hline 14,24 & $88,88 \mathrm{bc}$ & $0,15 \mathrm{~cd}$ & 47,5 & $30,8 b c$ & $18,7 b c$ & $26,5 b$ & $42,5 \mathrm{cde}$ \\
\hline 28,48 & $100 \mathrm{c}$ & $0,11 \mathrm{~d}$ & 95 & $41,8 \mathrm{c}$ & $30,5 \mathrm{bc}$ & $29,1 \mathrm{~b}$ & $47,5 \mathrm{de}$ \\
\hline 56,96 & $100 \mathrm{c}$ & $0,11 \mathrm{~d}$ & 190 & $47,4 \mathrm{c}$ & $37,3 \mathrm{c}$ & $44,9 \mathrm{c}$ & $55 \mathrm{e}$ \\
\hline $\begin{array}{l}\mathrm{CL}(\mathrm{E})_{50} \\
\left(\mathrm{mg} \mathrm{L}^{-1}\right)\end{array}$ & $2,5^{\mathrm{a}}$ & ND & & 189 & 451 & 262 & 111 \\
\hline
\end{tabular}

Tabla 2 - Efecto del metamidofos en el porcentaje de mortalidad de adultos de Orius insidiosus (Anthocoridae) de 1 a 12 h. Letras minúsculas iguales en una misma columna indican que los porcentajes de mortalidad son estadísticamente iguales $(\mathrm{p} \geq 0,05) . \mathrm{a}=$ metamidofos $\left(\right.$ Monofos $\left(\right.$, Clase Ia). $\mathrm{b}=$ metamidofos (Tamaron ${ }^{\circledR}$, Clase Ib).

\begin{tabular}{ccccc}
\hline Tiempo & $\mathbf{1 - 2} \mathbf{h}$ & $\mathbf{3 ~ h}$ & $\mathbf{6} \mathbf{h}$ & $\mathbf{1 2} \mathbf{~ h}$ \\
\hline Ia $\left(\mathrm{mg} \mathrm{L}^{-1}\right)^{\mathrm{a}}$ & & & & \\
Control & $0 \mathrm{a}$ & $0 \mathrm{a}$ & $0 \mathrm{a}$ & $0 \mathrm{a}$ \\
11,9 & $0 \mathrm{a}$ & $7,8 \mathrm{a}$ & $9,4 \mathrm{~b}$ & $25,2 \mathrm{~b}$ \\
23,8 & $1,1 \mathrm{a}$ & $14,4 \mathrm{ab}$ & $30,4 \mathrm{c}$ & $59,1 \mathrm{c}$ \\
47,5 & $6,6 \mathrm{a}$ & $32,2 \mathrm{~b}$ & $49,7 \mathrm{~d}$ & $94,9 \mathrm{~d}$ \\
95 & $34,4 \mathrm{~b}$ & $85,5 \mathrm{c}$ & $100 \mathrm{e}$ & $100 \mathrm{~d}$ \\
190 & $61,1 \mathrm{c}$ & $94,4 \mathrm{c}$ & $100 \mathrm{e}$ & $100 \mathrm{~d}$ \\
$\mathrm{CL}_{50} \mathrm{mg} \mathrm{L}^{-1}$ & 144 & 52,3 & 37,8 & 19,3 \\
\hline $\mathrm{Ib}\left(\mathrm{mg} \mathrm{L}^{-1}\right)^{\mathrm{b}}$ & & & & \\
$\mathrm{Control}$ & $0 \mathrm{a}$ & $0 \mathrm{a}$ & $0 \mathrm{a}$ & $0 \mathrm{a}$ \\
11,9 & $0 \mathrm{a}$ & $13,3 \mathrm{~b}$ & $21,3 \mathrm{~b}$ & $47,8 \mathrm{~b}$ \\
23,8 & $2,2 \mathrm{a}$ & $33,3 \mathrm{c}$ & $54,4 \mathrm{c}$ & $67,7 \mathrm{c}$ \\
47,5 & $13,3 \mathrm{ab}$ & $39,9 \mathrm{c}$ & $69,3 \mathrm{c}$ & $83,3 \mathrm{~d}$ \\
95 & $17,7 \mathrm{~b}$ & $53,3 \mathrm{~d}$ & $69,3 \mathrm{c}$ & $81,5 \mathrm{~d}$ \\
190 & $37,7 \mathrm{c}$ & $74,4 \mathrm{e}$ & $86,4 \mathrm{~d}$ & $90,7 \mathrm{~d}$ \\
$\mathrm{CL}_{50} \mathrm{mg} \mathrm{L}^{-1}$ & 281 & 68,4 & 28,5 & 10,3 \\
\hline
\end{tabular}


Tabla 3 - Efecto del metamidofos en el porcentaje de mortalidad y de emergencia de adultos de Copidosoma koehleri (Encyrtidae) de 1 a 48 h. Letras minúsculas iguales en una misma columna indican que los porcentajes de mortalidad son estadísticamente iguales $(\mathrm{p} \geq 0,05) . \mathrm{a}=$ metamidofos (Monofos ${ }^{\circledR}$, Clase Ia). $\mathrm{b}=$ metamidofos (Tamaron $\AA$, Clase Ib).

\begin{tabular}{|c|c|c|c|c|c|c|c|}
\hline Tiempo & $1-2 \mathrm{~h}$ & $3 \mathbf{h}$ & $6 \mathrm{~h}$ & $12 \mathrm{~h}$ & $24 \mathrm{~h}$ & $48 \mathrm{~h}$ & $\%$ Emergencia \\
\hline \multicolumn{8}{|l|}{$\mathrm{Ia}\left(\mathrm{mg} \mathrm{L}^{-1}\right)^{\mathrm{a}}$} \\
\hline Control & $0 \mathrm{a}$ & $0 \mathrm{a}$ & $0 \mathrm{a}$ & $0 \mathrm{a}$ & $0 \mathrm{a}$ & $0 \mathrm{a}$ & $87,0 \mathrm{a}$ \\
\hline 11,9 & $0 \mathrm{a}$ & $0 \mathrm{a}$ & $3,3 \mathrm{a}$ & $23,2 b$ & $70,8 b$ & $49,7 b$ & $89,0 \mathrm{a}$ \\
\hline 23,8 & $0 \mathrm{a}$ & $1,1 \mathrm{a}$ & $7,7 \mathrm{a}$ & $87,7 \mathrm{c}$ & $85,4 b$ & $89,9 c$ & $88,7 \mathrm{a}$ \\
\hline 47,5 & $0 \mathrm{a}$ & $12,1 b$ & $50 \mathrm{~b}$ & $100 \mathrm{~d}$ & $100 \mathrm{c}$ & $100 \mathrm{~d}$ & $91,2 \mathrm{a}$ \\
\hline 95 & $13,3 b$ & $47,7 \mathrm{c}$ & $94,4 \mathrm{c}$ & $100 \mathrm{~d}$ & $100 \mathrm{c}$ & $100 \mathrm{~d}$ & $89,7 \mathrm{a}$ \\
\hline 190 & $19,9 b$ & $58,8 \mathrm{c}$ & $100 \mathrm{c}$ & $100 \mathrm{~d}$ & $100 \mathrm{c}$ & $100 \mathrm{~d}$ & $75,9 b$ \\
\hline $\mathrm{CL}(\mathrm{E})_{50} \mathrm{mg} \mathrm{L}^{-1}$ & $>190$ & 130 & 45,1 & 15,5 & 8,35 & 12,1 & ND \\
\hline \multicolumn{8}{|l|}{$\mathrm{Ib}\left(\mathrm{mg} \mathrm{L}^{-1}\right)^{\mathrm{b}}$} \\
\hline Control & $0 \mathrm{a}$ & $0 \mathrm{a}$ & $0 \mathrm{a}$ & $0 \mathrm{a}$ & $0 \mathrm{a}$ & $0 \mathrm{a}$ & $91,9 \mathrm{a}$ \\
\hline 11,9 & $0 \mathrm{a}$ & $0 \mathrm{a}$ & $1,1 \mathrm{a}$ & $7,7 \mathrm{a}$ & $43,6 b$ & $86,5 b$ & $91,1 \mathrm{a}$ \\
\hline 23,8 & $0 \mathrm{a}$ & $0 \mathrm{a}$ & $2,2 \mathrm{a}$ & $14,4 \mathrm{~b}$ & $44,9 b$ & $88,5 b$ & $92,7 \mathrm{a}$ \\
\hline 47,5 & $0 \mathrm{a}$ & $0 \mathrm{a}$ & $7,8 \mathrm{a}$ & $57,7 \mathrm{c}$ & $94,6 \mathrm{c}$ & $100 \mathrm{c}$ & $91,8 \mathrm{a}$ \\
\hline 95 & $0 \mathrm{a}$ & $6,6 a$ & $51,8 b$ & $93,3 d$ & $100 \mathrm{c}$ & $100 \mathrm{c}$ & $85,3 \mathrm{a}$ \\
\hline 190 & $12,2 \mathrm{~b}$ & $53,2 b$ & $92,2 \mathrm{c}$ & $100 \mathrm{~d}$ & $100 \mathrm{c}$ & $100 \mathrm{c}$ & $85,7 \mathrm{a}$ \\
\hline $\mathrm{CL}(\mathrm{E})_{50} \mathrm{mg} \mathrm{L}^{-1}$ & $>190$ & 183 & 91,2 & 39,7 & 17,9 & 11,1 & $\mathrm{ND}$ \\
\hline
\end{tabular}

Tabla 4 - Efecto del metamidofos en el porcentaje de mortalidad de adultos de Leptomastidea abnormis (Encyrtidae) de 1 a 12 h. Letras minúsculas iguales en una misma columna indican que los porcentajes de mortalidad son estadísticamente iguales $(\mathrm{p} \geq 0,05)$. a $=$ metamidofos (Monofos ${ }^{\circledR}$, Clase Ia). b = metamidofos (Tamaron ${ }^{\circledR}$, Clase Ib).

\begin{tabular}{ccccc}
\hline Tiempo & $\mathbf{1 - 2} \mathbf{h}$ & $\mathbf{3 ~ h}$ & $\mathbf{6} \mathbf{h}$ & $\mathbf{1 2} \mathbf{~ h}$ \\
\hline${\mathrm{Ia}\left(\mathrm{mg} \mathrm{L}^{-1}\right)^{\mathrm{a}}}$ & & & & \\
Control & $0 \mathrm{a}$ & $0 \mathrm{a}$ & $0 \mathrm{a}$ & $0 \mathrm{a}$ \\
11,9 & $35,5 \mathrm{~b}$ & $74,4 \mathrm{~b}$ & $95,8 \mathrm{~b}$ & $92,1 \mathrm{~b}$ \\
23,8 & $76,6 \mathrm{c}$ & $98,8 \mathrm{c}$ & $98,7 \mathrm{~b}$ & $96,1 \mathrm{~b}$ \\
47,5 & $97,7 \mathrm{~d}$ & $100 \mathrm{c}$ & $100 \mathrm{~b}$ & $100 \mathrm{~b}$ \\
95 & $100 \mathrm{~d}$ & $100 \mathrm{c}$ & $100 \mathrm{~b}$ & $100 \mathrm{~b}$ \\
190 & $100 \mathrm{~d}$ & $100 \mathrm{c}$ & $100 \mathrm{~b}$ & $100 \mathrm{~b}$ \\
$\mathrm{CL}_{50} \mathrm{mg} \mathrm{L}^{-1}$ & 15 & 9 & 2 & 2,6 \\
\hline $\left.\mathrm{Ib}_{(\mathrm{mg} \mathrm{L}}^{-1}\right)^{\mathrm{b}}$ & & & & \\
$\mathrm{Control}^{1}$ & $0 \mathrm{a}$ & $0 \mathrm{a}$ & $0 \mathrm{a}$ & $0 \mathrm{a}$ \\
11,9 & $0 \mathrm{a}$ & $0 \mathrm{a}$ & $1,5 \mathrm{a}$ & $70,1 \mathrm{~b}$ \\
23,8 & $0 \mathrm{a}$ & $0 \mathrm{a}$ & $20,7 \mathrm{~b}$ & $93,1 \mathrm{c}$ \\
47,5 & $0 \mathrm{a}$ & $14,4 \mathrm{~b}$ & $80,7 \mathrm{c}$ & $95,3 \mathrm{c}$ \\
95 & $31,1 \mathrm{~b}$ & $95,5 \mathrm{c}$ & $100 \mathrm{~d}$ & $100 \mathrm{c}$ \\
190 & $51,1 \mathrm{c}$ & $94,4 \mathrm{c}$ & $100 \mathrm{~d}$ & $100 \mathrm{c}$ \\
$\mathrm{CL}_{50} \mathrm{mg} \mathrm{L}^{-1}$ & 167 & 66,8 & 32,9 & 6,7 \\
\hline
\end{tabular}


Tabla 5 - Resumen de la evaluación de Riesgos Ambientales (ERA) del metamidofos (Ia y Ib) con ocho organismos no destinatarios terrestres. Exposición $=\mathbf{C E E}=$ concentración efectiva ambiental. $\mathrm{CR}=$ cociente de riesgo $=$ Exposición $/$ Toxicidad. $\mathrm{LOC}=$ nivel critico.

\begin{tabular}{|c|c|c|c|c|c|c|c|}
\hline Especie & Estimador & $\begin{array}{l}\text { Tiempo } \\
\text { (h) }\end{array}$ & Toxicidad & Exposición & $\begin{array}{c}\text { Exp / } \\
\text { Toxicidad } \\
\text { RQ } \\
\end{array}$ & LOC & Riesgo \\
\hline \multicolumn{8}{|l|}{ Ia } \\
\hline $\begin{array}{l}\text { Porcellio laevis } \\
\text { (hembras) }\end{array}$ & $\begin{array}{c}\mathrm{DL}_{50} \\
\left(\mathrm{mg} \mathrm{kg}^{-1}\right)\end{array}$ & 48 & 28,8 & 686 & 23,8 & 0,5 & $\mathrm{Si}$ \\
\hline $\begin{array}{l}\text { Porcellio laevis } \\
\text { (hembras con } \\
\text { huevos) }\end{array}$ & $\underset{\left(\mathrm{mg} \mathrm{kg}^{-1}\right)}{\mathrm{DL}_{50^{-}}}$ & 48 & 22,8 & 686 & 30,1 & 0,5 & $\mathrm{Si}$ \\
\hline $\begin{array}{l}\text { Cryptolaemus } \\
\text { mountrouzieri } \\
\text { (adultos) }\end{array}$ & $\underset{\left(\mathrm{mg} \mathrm{L}^{-1}\right)}{\mathrm{CL}_{50}}$ & 4 & $<600$ & 2.100 & 3 & 0,5 & $\mathrm{Si}$ \\
\hline $\begin{array}{c}\text { Chrysoperla } \\
\text { externa } \\
\text { (huevos) }\end{array}$ & $\begin{array}{l}\mathrm{CE}_{50} \\
\left(\mathrm{mg} \mathrm{L}^{-1}\right)\end{array}$ & 48 & 189 & 2.100 & 11,1 & 1 & $\mathrm{Si}$ \\
\hline $\begin{array}{l}\text { Chrysoperla } \\
\text { externa } \\
\text { (larvas) }\end{array}$ & $\begin{array}{l}\mathrm{CL}_{50} \\
\left(\mathrm{mg} \mathrm{L}^{-1}\right) \\
\mathrm{CL}\end{array}$ & 48 & 262 & 2.100 & 8,0 & 0,5 & $\mathrm{Si}$ \\
\hline $\begin{array}{l}\text { Orius insidiosus } \\
\quad \text { (adultos) }\end{array}$ & $\begin{array}{c}\mathrm{CL}_{50} \\
\left(\mathrm{mg} \mathrm{L}^{-1}\right)\end{array}$ & 12 & 19,3 & 2.100 & 108 & 0,5 & $\mathrm{Si}$ \\
\hline $\begin{array}{c}\text { Leptomastidea } \\
\text { abnormis } \\
\text { (adultos) }\end{array}$ & $\underset{\left(\mathrm{mg} \mathrm{L}^{-1}\right)}{\mathrm{CL}_{50}}$ & 12 & 2,6 & 2.100 & 807 & 0,5 & $\mathrm{Si}$ \\
\hline $\begin{array}{l}\text { Copidosoma } \\
\text { koehleri } \\
\text { (adultos) } \\
\end{array}$ & $\underset{\left(\mathrm{mg} \mathrm{L}^{-1}\right)}{\mathrm{CL}_{50}}$ & 48 & 12,1 & 2.100 & 173 & 0,5 & $\mathrm{Si}$ \\
\hline \multicolumn{8}{|l|}{$\mathrm{Ib}$} \\
\hline $\begin{array}{l}\text { Eisenia foetida } \\
\text { Porcellio laevis }\end{array}$ & $\begin{array}{c}\mathrm{DL}_{50} \\
\left(\mathrm{mg} \mathrm{kg}^{-1}\right)\end{array}$ & 144 & 2,5 & 686 & 274 & 0,5 & $\mathrm{Si}$ \\
\hline $\begin{array}{l}\text { Porcellio laevis } \\
\quad \text { (neonato) }\end{array}$ & $\begin{array}{c}\mathrm{DL}_{50} \\
\left(\mathrm{mg} \mathrm{kg}^{-1}\right)\end{array}$ & 48 & 20,3 & 686 & 33,7 & 0,5 & $\mathrm{Si}$ \\
\hline $\begin{array}{l}\text { Porcellio laevis } \\
\quad \text { (machos) }\end{array}$ & $\begin{array}{c}\mathrm{DL}_{50} \\
\left(\mathrm{mg} \mathrm{kg}^{-1}\right)\end{array}$ & 48 & 13,4 & 686 & 51,2 & 0,5 & $\mathrm{Si}$ \\
\hline $\begin{array}{l}\text { Porcellio laevis } \\
\text { (hembras) }\end{array}$ & $\begin{array}{c}\mathrm{DL}_{50} \\
\left(\mathrm{mg} \mathrm{kg}^{-1}\right)\end{array}$ & 48 & 16,4 & 686 & 41,8 & 0,5 & $\mathrm{Si}$ \\
\hline $\begin{array}{l}\text { Podisus nigrsipinus } \\
\text { (ninfas) }\end{array}$ & $\begin{array}{c}\mathrm{CL}_{50} \\
\left(\mathrm{mg} \mathrm{L}^{-1}\right)\end{array}$ & 48 & $>570$ & 2.100 & 3,7 & 0,5 & $\mathrm{Si}$ \\
\hline $\begin{array}{l}\text { Chrysoperla } \\
\text { externa } \\
\text { (huevos) }\end{array}$ & $\underset{\left(\mathrm{mg} \mathrm{L}^{-1}\right)}{\mathrm{CE}_{50}}$ & 48 & 451 & 2.100 & 4,7 & 1 & $\mathrm{Si}$ \\
\hline $\begin{array}{l}\text { Chrysoperla } \\
\text { externa } \\
\text { (larvas) }\end{array}$ & $\underset{\left(\mathrm{mg} \mathrm{L}^{-1}\right)}{\mathrm{CL}_{50}}$ & 48 & 111 & 2.100 & 18,9 & 0,5 & $\mathrm{Si}$ \\
\hline $\begin{array}{l}\text { Orius insidiosus } \\
\quad \text { (adultos) }\end{array}$ & $\begin{array}{c}\mathrm{CL}_{50} \\
\left(\mathrm{mg} \mathrm{L}^{-1}\right)\end{array}$ & 12 & 10,3 & 2.100 & 203 & 0,5 & $\mathrm{Si}$ \\
\hline $\begin{array}{l}\text { Leptomastidea } \\
\text { abnormis (adultos) }\end{array}$ & $\left(\mathrm{CL}_{50} \mathrm{~L}^{-1}\right)$ & 12 & 6,7 & 2.100 & 313 & 0,5 & $\mathrm{Si}$ \\
\hline $\begin{array}{c}\text { Copidosoma } \\
\text { koehleri } \\
\text { (adultos) }\end{array}$ & $\left(\begin{array}{c}50 \\
\left(\mathrm{mg} \mathrm{L}^{-1}\right)\end{array}\right.$ & 48 & 11,1 & 2.100 & 189 & 0,5 & $\mathrm{Si}$ \\
\hline
\end{tabular}




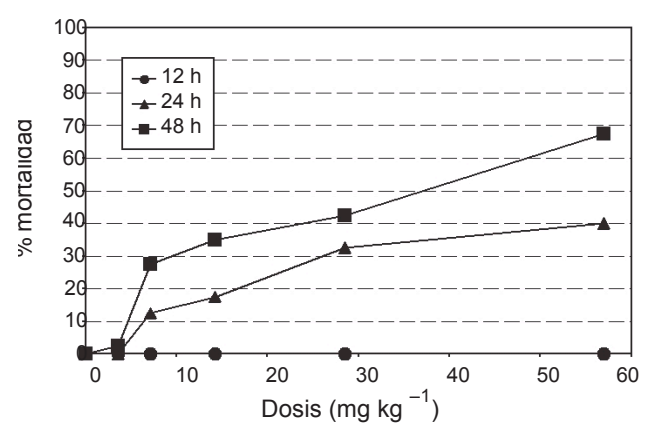

Figura 1a - Efecto del metamidofos (Ia) en el porcentaje de mortalidad de hembras de Porcellio laevis (Isopoda) de 3 a $48 \mathrm{~h}$ de exposición.

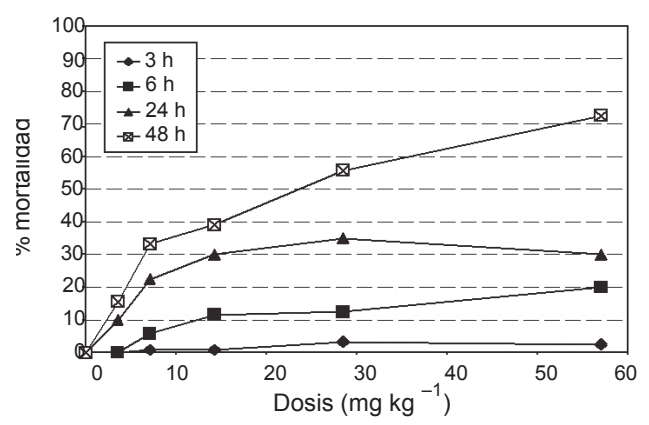

Figura 1c - Efecto del metamidofos (Ib) en el porcentaje de mortalidad de neonatos de Porcellio laevis (Isopoda) de 3 a $48 \mathrm{~h}$ de exposición.

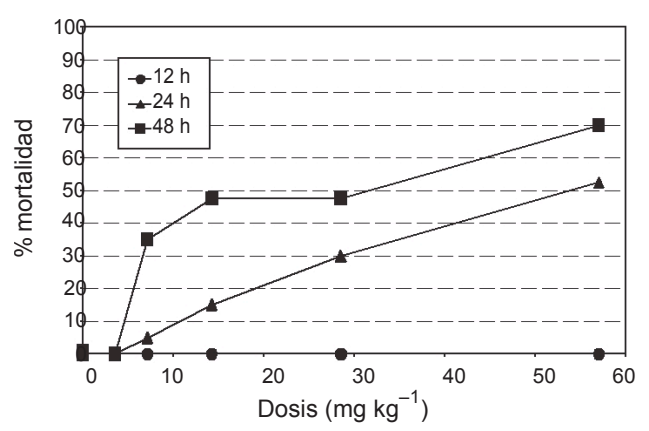

Figura 1b - Efecto del metamidofos (Ia) en el porcentaje de mortalidad de hembras con huevos de Porcellio laevis (Isopoda) de 3 a $48 \mathrm{~h}$ de exposición.

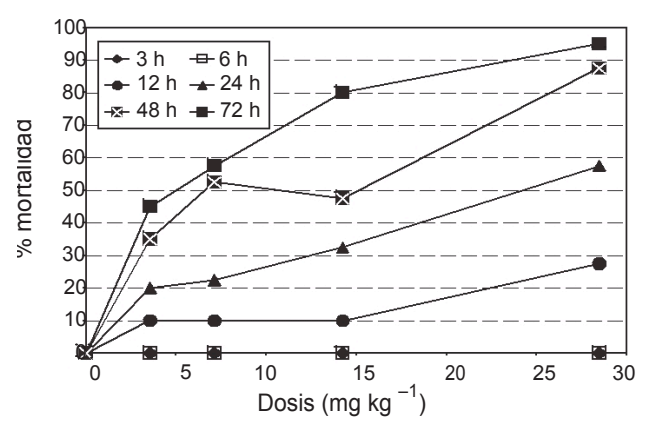

Figura 1d - Efecto del metamidofos (Ib) en el porcentaje de mortalidad de machos de Porcellio laevis (Isopoda) de 3 a $72 \mathrm{~h}$ de exposición.

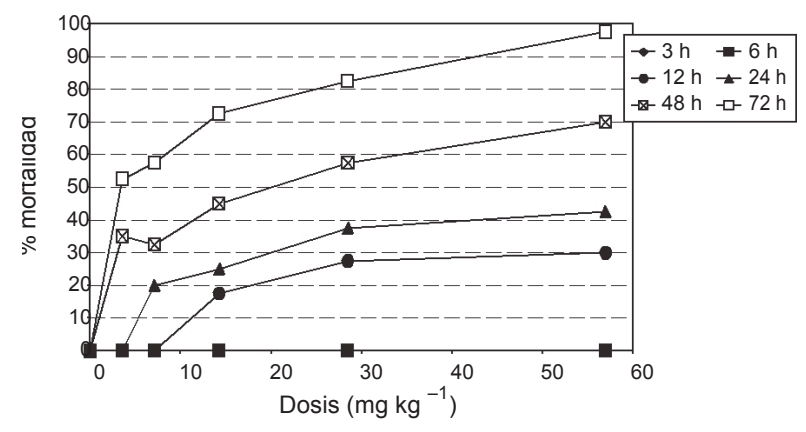

Figura 1e - Efecto del metamidofos (Ib) en el porcentaje de mortalidad de hembras de Porcellio laevis (Isopoda) de 3 a $72 \mathrm{~h}$ de exposición. 
Las mayores toxicidades observadas sobre los organismos del suelo E. foetida y P. laevis, podría explicarse posiblemente a que el metamidofos tiene un tiempo de vida media en la hoja menor a un día, y en cambio en el suelo es un tiempo menor a 3 días donde viven E. foetida y P. laevis (Evaristo \& Baptista, 2002). Entonces la rápida degradación del producto en el suelo podrian estar influenciando en la toxicidad del metamidofos. Por otro lado, en el Perú, son muy comunes las aplicaciones del metamidofos al doble de las concentraciones recomendadas y de dos a nueve aplicaciones continuas para el control de las plagas e una sola campaña por el agricultor (USEPA, 1998). Este hecho originaría un mayor impacto en la fauna benéfica aérea, al incrementar los niveles de exposición a las mismas. En el presente trabajo, el análisis ecotoxicológico de ocho especies animales con diferentes nichos ecológicos para determinar la selectividad del metamidofos, podría contribuir a tomar medidas más idóneas de mitigación para su empleo en MIP.

\section{REFERENCIAS}

ARMENTA, R., MARTÍNEZ, A. M., CHAPMAN, J. W., MAGALlANES, R., GOULSON, D., CABALlERO, P., CAVE, R. D., CISNEROS, J., VALLE, J., CASTILLEJOS, V., PENAGOS, D. I., GARCÍA, L. F. \& WILLIAMS, T., 2003, Impact of a nucleopolyhedrovirus bioinsecticide and selected synthetic insecticides on the abundance of insect natural enemies on maize in southern Mexico. J. Econ. Entomol., 96: 649-661.

CADÉE, N. \& JACQUES J. M. A., 1997, Host selection and sex allocation in Leptomastidea abnormis, a parasitoid of the citrus mealybug Planococcus citri. Entomol. Exp. Appl., 83: 277-284.

CALOW, P., 1993, Handbook of ecotoxicology. Vol. I. Sheffield, Blackwell, Science Ltd., UK, 478 p.

CARVALHO, G. A., DRUMMOND, F. A., ULHOA, J. L. R. \& ROCHA, L. C. D., 2002a, Effect of insecticides on Orius insidiosus (Say, 1832) (Hemiptera: Anthocoridae). Cienc. Agrotec. Lavras, 26: 52-56.

CARVAlho, G. A., CARVAlHO, C. F., SOUZA, B. \& ULHOA, J. L. R., 2002b, Selectividade de insecticidas a Chrysoperla externa (Hagen) (Neuroptera: Chrysopidae). Neotropical Entomol., 31: 615-621.

CHARROIS, J. W. A., MCGILL, W. B. \& FROESE, K. L., 2001, Acute toxicity of creosote-contaminated soils to Eisenia fetida: a survival-based approach. Environ. Toxicol. Chem., 20: 2594-2603.

CURRIE, M., HODSON, M. E., ARNOLD, E. E. \& LANGDON, C. J., 2005. Single versus multiple occupancy-effects on toxicity parameters measured on Eisenia fetida in lead nitrate-treated soil. Environ. Toxicol. Chem., 24: 110-116.

EPP0, 2002, Safe use of biological control. Normes OEPP. EPPO standards. Bul. OEPP/EPPO, 32: 443-445.

EVANGELISTA, W. S. JR., SILVA-TORRES, C. S. A. \& TORRES, J. B., 2002. Toxicidade de Lufenurom para Podisus nigrispinus (Dallas) (Heteroptera: Pentatomidae). Neotropical Entomol., 31: 319-326.

EVANGELISTA W. S. JR., GONDIM M. G. C. JR., TORRES J. B. \& MARQUES, E. J., 2004, Fitofagia de Podisus nigrispinus em algodoeiro e plantas daninhas. Pesq. Agropecu. Bras., 39: 413-420.

EVARISTO, A. \& BAPTISTA, G. C., 2002, Dislodgeable residues of metamidophos in staked tomatoes. Scientia Agricola, 59: 469-473.

FIEDLER, L., 1987, Assessment of chronic toxicity of selected insecticides to honey bees. J. Apic. Res., 26: 115-122.
FIGULS, M., CASTAÑE, C. \& GABARRA, R., 2006, Residual toxicity of some insecticides on the predatory bugs Dicyphus tamaninii and Macrolophus caliginosus. BioControl, 44: 89-98.

GONZALEZ-VALERO, J. F., CAMPBELL, P. J., FRITSCH, H. J., GRAU, R. \& ROMIJN, K., 2000, Exposure assessment for terrestrial non-target arthropods. J. Pest Science, 73: 163-168.

GOdoy, M. S., CARVAlho, G. A., MORAeS, J. C., COSME, L. V., GOUSSAIN, M. M.., CARVALHO, C. F. \& MORAIS, A. A., 2004, Seletividade de seis inseticidas utilizados en citros a pupas e adultos de Chrysoperla externa (Hagen) (Neuroptera: Chrysopidae). Neotropical Entomol., 33: 359-364.

HARVEY, J. A., CORLEY, L. S. \& STRAND, M. R., 2000, Competition induces adaptative shifts in caste ratios of polyembryonic wasp. Nature, 406: 183-186.

HELLING, B., REINECKE, S. A. \& REINECKE, A. J., 2000, Effects of the fungicide copper oxychloride on the growth and reproduction of Eisenia foetida (Oligochaeta). Ecotoxicol. Environ. Saf., 46: 108-116.

HUSSEIN, M. A., 1987, Anticholinesterase properties of methamidophos and acephate in insects and mammals. Bull. Environ. Contam. Toxicol., 38: 131-138.

IANNACONE, J. \& GUTIERREZ, A., 1999, Ecotoxicidad de los agroquímicos lindano y clorpirifos sobre el nematodo Panagrellus, la microalga Chlorella y el ensayo con Allium. Agric. Tec. (Chile), 59: 85-95.

IANNACONE, J. \& REYES, M. 2001, Efecto en las poblaciones de Bemisia tabaci (Homoptera: Aleyrodidae) y Liriomyza huidobrensis (Diptera: Agromyzidae) por los insecticidas botánicos neem y rotenona en el cultivo de tomate en el Perú. Rev. Colomb. Entomol., 27: 147-152.

IANNACONE, J. \& LAMAS, G., 2002, Efecto de dos extractos botánicos y de un insecticida convencional sobre el depredador Chrysoperla externa. Manejo Integrado de Plagas y Agroecología (Costa Rica), 65: 92-101.

IANNACONE, J. \& LAMAS, G., 2003, Efecto toxicológicos del nim, rotenona y cartap sobre tres microavispas parasitoides de plagas agrícolas en el Perú. Bol. San. Veg. Plagas, 29: 123-142.

IANNACONE, J. \& ALVARIÑO, L., 2004, Eisenia foetida (Savigny, 1826) (Annelida: Lumbricidae) como modelo ecotoxicológico para evaluar lindano y clorpirifos. Acta Zool. Lilloana, 48: 5-12.

IANNACONE, J. \& ALVARIÑO, L., 2005, Selectividad del insecticida cartap empleando bioensayos con organismos no destinatarios. Ecol. Apl., 4: 91-104.

IANNACONE, J., ALVARIÑO, L., CABALLERO, C. \& SÁNCHEZ, J., 2000, Cuatro ensayos ecotoxicológicos para evaluar lindano y clorpirifos. Gayana, 64: 139-146.

IANNACONE, J., ALAYO, M., ABANTO, M., SÁNCHEZ, J. \& ZAPATA, E., 2001, Porcellio laevis Latreille, 1804 (Isopoda: Porcellionidae) como bioindicador para evaluación de plomo. Rev. Per. Entomol., 42: 175-183.

IANNACONE, J., ALVARIÑO, L. \& CABALLERO, C., 2002, Empleo del caracol de agua dulce Physa venustula como herramienta ecotoxicológica para la evaluación de riesgo ambientales por plaguicidas. Agric. Téc. (Chile), 62: 212-225.

KAIRO, M. T. K., POLLARD, G. V., PETERKIN, D. D. \& LOPEZ, V. F., 2000, Biological control of the hibiscus mealybug, Maconellicoccus hirsutus Green (Hemiptera: Pseudococcidae) in the Caribbean. Integrated Pest. Manag. Rev., 5: 241-254.

LUDWIG, S. \& OETTING, R., 2001, Effect of spinosad on Orius insidiosus (Hemiptera: Anthocoridae) when used for Frankliniella occidentalis (Thysanoptera: Thripidae) control on greenhouse pot chrysanthemums. Florida Entomol., 84: 311-313. 
MACEDO, L. P. M., SOUZA, B., CARVAlHO, C. F. \& ECOLE, C. C., 2003, Influência do fotoperíodo no desenvolvimiento e na reprodução de Chrysoperla externa (Hagen) (Neuroptera: Chrysopidae). Neotropical Entomol., 32: 91-96.

MEDEIROS, R. S., RAMAlHO, F. S., ZANUNCIO, J. C. \& SERRÃO, J. E., 2003, Effect of temperature on life table parameters of Podisus nigrispinus (Het., Pentatomidae) fed with Alabama argillacea (Lep., Noctuidae) larvae. J. Appl. Entomol., 127: 209-213.

MOHAGHEGH, J., DE CLERCQ, P. \& TIRRY, L., 1999, Effects of rearing history and geographical origin on reproduction and body size of the predador Podisus nigrispinus (Heteroptera: Pentatomidae). European J. Entomol., 96: 69-72.

OBRYCKI, J. J. \& KRING, T. J., 1998, Predaceous coccinellidae in biological control. Ann. Rev. Entomol., 43: 295-321.

OECD, 1984, Guideline for testing chemicals 207, Earthworm acute toxicity test. Adopted: 4 April. Paris, France.

OECD, 2000, Guideline for testing chemicals. New Guideline. Earthworm reproduction test (Eisenia foetida/ andrei). Draft document. January 2000, Paris, France, 17 p.

OLIVEIRA, J. E. M., TORRES, J. B., CARRANO-MOREIRA, A. F. \& RAMALHO, F. S., 2002, Biologia de Podisus nigrispinus predando lagartas de Alabama argillacea em campo. Pesq. Agropecu. Bras., 37: 7-14.

PETCHARAT, J., 1998, Effects of insecticides and fungicides used in guava orchard on parasitoid Diachasmimorpha longicaudata. Khon Kaen Agriculture, 26: 28-32.

PRIETO, A., MOLERO, D., GONZALEZ, G., BUSCEMA, I., ETTIENE, G. \& MEDINA, D., 2002, Persistence of methamidophos, diazinon, and malathion in tomatoes. Bull. Environ. Contam. Toxicol., 69: 479-485.

RAMANI, S., POORANI, J. \& BHUMANNAVAR, B. S., 2002, Spiralling whitefly, Aleurodicus dispersus, in India. Biocontrol, New and Information, 23: 55-62.

ROMBKE, J., JANSCH, S., JUNKER, T., POHL, B., SCHEFFCYK, A. \& SCHALLNA, H. J., 2006, Improvement of the applicability of ecotoxicological tests with earthworms, springtails, and plants for the assessment of metals in natural soils. Ecotoxicol. Environ. Chem., 25: 776-787.

SALAZAR, E. R. \& ARAYA, J. E., 2001, Respuesta de la polilla del tomate, Tuta absoluta (Meyrick), a insecticidas en arica. Agric. Téc. (Chile), 61: 429-435.

SCHUMUCK, R., 1997, Effects of Euparen ${ }^{\circledR}$ M on honey bees and selected beneficial arthropods-Information about the use of the pesticide during blossom and in IPM cultures. Plfanz.-Nachr. Bayer, 50: 233-246.

SERRANO, M. S. \& LAPOINTE, S. L., 2002, Evaluation of host plants and a meridic diet for rearing Maconellicoccus hirsutus (Hemiptera: Pseudococcidae) and its parasitoid Anagyrus kamali (Hymenoptera: Encyrtidae). Florida Entomol., 85: 417-425.

SOSA-GOMEZ, D. R., CORSO, I. C. \& MORALES, L., 2001, Insecticide resistance to Endosulfan, Monocrotophos and Metamidophos in the neotropical brown stink bug, Euschistus heros (F.). Neotropical Entomol., 30: 317-320.
STOORVOGEL, J., JARAMILLO, R., MERINO, R. \& KOSTEN, S. 2003, Plaguicidas en el medio ambiente. In: D. Yanggen, C. Crissman \& P. Espinosa (eds.), Los plaguicidas: impactos en producción, saludy medio ambiente en Carchi, Ecuador. Centro Internacional de la Papa, Instituto Nacional Autónomo de Investigaciones Agropecuarias, Ed. Abya-Yala, Quito, Ecuador.

STUDEBAKER, G. L. \& KRING, T. J., 2003, Effects of insecticides on Orius insidiosus (Hemiptera: Anthocoridae), measured by field, greenhouse and Petri dish bioassays. Florida Entomol., 86: 178-185.

THRONE, J. E., WEAVER, D. K., CHEW, V. \& BAKER, J. E., 1995, Probit analysis of correlated data: multiple observations over time at one concentration. J. Econ. Entomol., 88: 1510-1512.

TILLMAN, P. G. \& MULLINIX, B. G. JR., 2004, Comparison of susceptibility of pest Euschistus servus and predator Podisus maculiventris (Heteroptera: Pentatomidae) to selected insecticides. J. Econ. Entomol., 97: 800-806.

TINGLE, C. C. D. \& COPLAND, M. J. W., 1988, Predicting development of the mealybug parasitoids Anagyrus pseudococci, Leptomastix dactylopii and Leptomastidea abnormis under glasshouse conditions. Entomol. Exp. Appl., 46: 19-28.

TORRES, J. B., SILVA-TORRES, C. S. A., SILVA, M. R. \& FERREIRA, J. F., 2002, Compatibilidade de inseticidas e acaricidas com o percevejo predador Podisus nigrispinus (Dallas) (Heteroptera: Pentatomidae) em algodoeiro. Neotropical Entomol., 31: 311-317.

TORRES, J. B., SILVA-TORRES, C. S. \& BARROS, R., 2003, Relative effects of the insecticide thiamethoxam on the predator Podisus nigrispinus and the tobacco whitefly Bemisia tabaci in nectaried and nectariless cotton. Pest. Management Sci., 59: 315-23.

USEPA, 1998, Metamidophos: a revision of EFED risk assessment for the reregistration elegibility Decision (RED) document to include registrant's comments. Draft document, January, 1998. 78p.

VERMEULEN, L. A., REINECKE, A. J. \& REINECKE, S.A., 2001, Evaluation of the fungicide manganese-zinc ethylene bis (dithiocarbamate) (manozeb) for sublethal and acute toxicity to Eisenia foetida (Oligochaeta). Ecotoxicol. Environ. Saf., 48: 183-189.

VIVAN, L. M., TORRES, J. B., BARROS, R. \& VEIGA, A. F., 2002, Population growth rate of the depredating Podisus nigrispinus (Heteroptera: Pentatomidae) and of the Tuta absoluta (Leptoptera: gelechiidae) in wintering place. Rev. Biol. Trop., 50: 145-153.

WU, G., JIANG, S. \& MIYATA, T., 2004a, Seasonal changes of metamidophos susceptibility and biochemical properties in Plutella xylostella (Lepidoptera: Yponomeutidae) and its parasitoid Cotesia plutella (Hymenoptera: Braconidae). J. Econ. Entomol., 97: 1689-1698.

WU, G., JIANG, S. \& MIYATA, T., 2004b, Effects of sinergists on toxicity of six insecticides in parasitoid Diaretiella rapae (Hymenoptera: Aphidiidae). J. Econ. Entomol., 97: 2057-2066.

ZACARIAS, M. S., MORAES, J. C., CASTRO-DINIZ, L., CIOCIOLA, A. I. JR. \& DAMASCENO, A. G., 1998, Selectivity of insect growth regulators to eggs and nymphs of Podisus nigrispinus (Dallas) (Hemiptera: Pentatomidae). Ciênc. Agrotec, 22: 194-198. 